\title{
Balloon dilatation of a stenosed modified (polytetrafluoroethylene) Blalock-Taussig shunt
}

\author{
J M PARSONS, E J LADUSANS, S A QURESHI \\ From the Department of Paediatric Cardiology, Guy's Hospital, London
}

SUMMARY A 17 month old girl with tricuspid atresia, ventricular septal defect, subvalvar and valvar pulmonary stenosis, and increasing cyanosis had angiographic evidence of proximal stenosis of a right modified ( $5 \mathrm{~mm}$ diameter) Blalock-Taussig shunt. She underwent palliative balloon angioplasty with a $6 \mathrm{~mm}$ Schneider balloon catheter. Successful dilatation was achieved without complication. Four months later there was subjective clinical improvement with a rise in systemic arterial saturation. Repeat angiography showed patency of the shunt without restenosis or formation of an aneurysm.

Balloon angioplasty has been used as a palliative treatment for the relief of baffle obstruction after Mustard's operation, ${ }^{1}$ in patients with symptomatic tetralogy of Fallot, ${ }^{2}$ and after stenosis of classic Blalock-Taussig shunts. ${ }^{3}$ We report successful balloon dilatation of a stenosed modified BlalockTaussig shunt (polytetrafluoroethylene graft) in a 17 month old girl with tricuspid atresia, ventricular septal defect, and subvalvar and valvar pulmonary stenosis.

\section{Case report}

A baby girl weighing $3.6 \mathrm{~kg}$ presented with central cyanosis when she was six days old. Physical examination showed an ejection systolic murmur maximal along the lower sternal border. The electrocardiogram showed sinus rhythm, a superior mean QRS frontal axis, and left ventricular dominance. Cross sectional echocardiography showed tricuspid atresia with concordant ventriculoarterial connections, a non-restrictive ventricular septal defect, a hypoplastic right ventricle, and subvalvar and valvar pulmonary stenosis. She was initially managed conservatively but after three months she became increasingly cyanosed and underwent a modified right Blalock-Taussig shunt with a $5 \mathrm{~mm}$ diameter polytetrafluoroethylene graft.

When she was 17 months old increasing cyanosis and a haemoglobin concentration of $17.6 \mathrm{~g} / 1$ prompted cardiac catheterisation, which showed aortic oxygen saturation of $73 \%$. The main pulmonary

Requests for reprints to Dr S A Qureshi, Department of Paediatric Cardiology, Guy's Hospital, St Thomas Street, London SE1 9RT. artery pressure was $10 / 7 \mathrm{~mm} \mathrm{Hg}$ (mean 8) with a simultaneous aortic pressure of $100 / 50 \mathrm{~mm} \mathrm{Hg}$ (mean 60). Angiography showed moderate stenosis of the modified Blalock-Taussig shunt at the site of the proximal anastomosis (fig 1). There was acquired pulmonary atresia and the pulmonary arteries were of normal size with no evidence of localised stenosis or kinking. Balloon dilatation was performed. She was systemically heparinised with $50 \mathrm{IU} / \mathbf{k g}$. A straight 0.020 inch exchange guide wire was passed from the

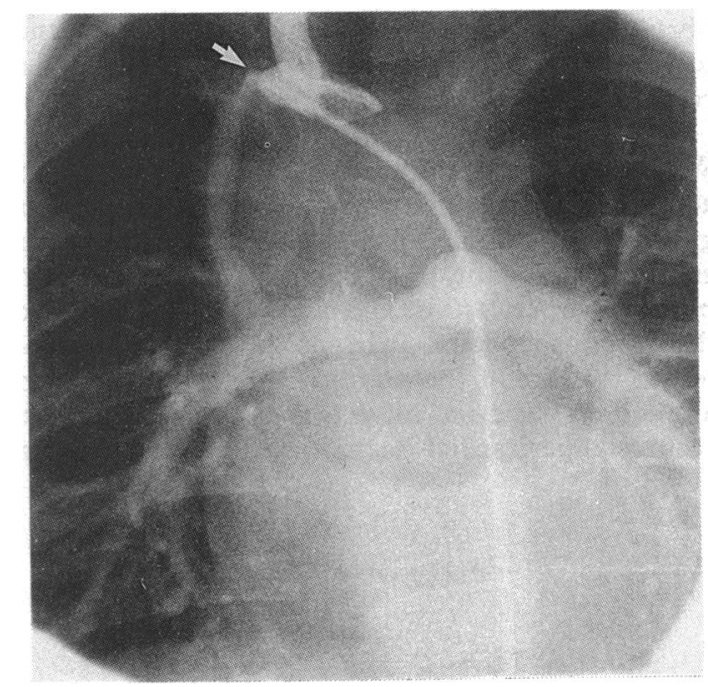

Fig 1 Shunt angiogram in anteroposterior projection taken before balloon dilatation showing a right sided modified Blalock-Taussig shunt with a stenosis at the site of the proximal anastomosis to the right subclavian artery (arrow). 


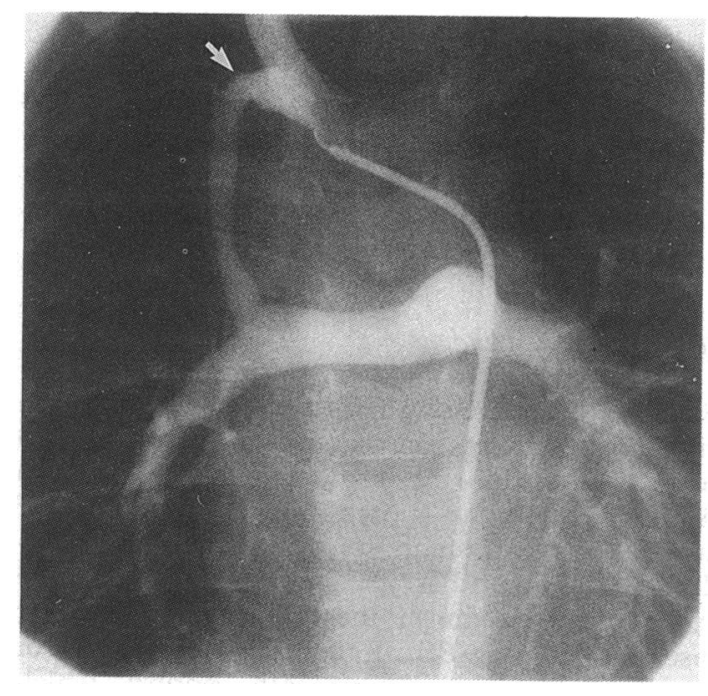

Fig 2 Repeat shunt angiogram in anteroposterior projection taken four months after balloon dilatation showing effective relief of the previously stenotic site (arrow).

femoral artery, into the descending aorta, through the shunt, and placed in the distal right lower lobe branch pulmonary artery. A Schneider balloon catheter (6 mm diameter, $15 \mathrm{~mm}$ balloon length) on a 5 French shaft was positioned across the site of the proximal stenosis and inflated twice. There were no complications either during or after inflation. Repeat angiography showed satisfactory relief of the proximal stenotic site. Pulse oximetry showed a transcutaneous oxygen saturation of $80 \%$ after the procedure. There were no early complications after this procedure and treatment with aspirin $(10 \mathrm{mg} / \mathrm{kg} /$ $24 \mathrm{~h})$ and dipyridamole $(6 \mathrm{mg} / \mathrm{kg} / 24 \mathrm{~h})$ was started.

Four months later, when she was 21 months old, she was less cyanosed. At repeat cardiac catheterisation the aortic oxygen saturation was $76 \%$. Repeat angiography showed that the proximal anastomotic site was patent with no evidence of restenosis or formation of an aneurysm (fig 2 ).

\section{Discussion}

When at the age of 17 months our patient became more cyanosed and had angiographic evidence of a stenosed shunt, the therapeutic options included either a second systemic to pulmonary arterial shunt or a Fontan-type procedure. The younger a patient is when a Fontan-type operation is performed the higher the risk ${ }^{4}$; hospital mortality is $25 \%$ for operations carried out between 12 and 24 months. ${ }^{5}$ Although the hospital mortality for a second shunt operation is likely to be low, complications such as distortion and kinking of the pulmonary artery ${ }^{6}$ or pulmonary hypertension ${ }^{7}$ may increase the operative risks of a subsequent Fontan-type procedure. Because balloon angioplasty was successful for palliation of patients with stenosed classic BlalockTaussig shunts ${ }^{3}$ we decided to use this technique in our patient to delay a Fontan-type procedure.

Balloon angioplasty achieved adequate palliation for four months without complications. There was an improvement in cyanosis, haemoglobin concentrations did not increase, and angiography did not show early restenosis or aneurysm formation. She remains suitable for a Fontan-type procedure.

There were no technical problems or complications associated with this procedure. The choice of balloon size was related to the size of the prosthetic shunt rather than specific angiographic measurements. For dilatation of a classic Blalock-Taussig shunt Fischer et al measured the diameter of the shunt immediately proximal to the stenosis and they found that a balloon with a diameter of equal size was ineffective; they used a balloon with a diameter that was $2 \mathrm{~mm}$ larger and a balloon to shunt ratio of $150 \%{ }^{3}$ We recommend caution in using such a ratio for dilating prosthetic materials. Aneurysm formation and vessel and graft rupture are potential complications.

We believe that balloon angioplasty of stenosed modified Blalock-Taussig shunts is feasible and safe and may produce palliation in selected patients. Until further studies have been performed we advise caution in using balloon diameters that are larger than the shunt diameter.

\section{References}

1 Kirk CR, Gibbs JL, Wilkinson JL, Wilson N, Dickinson DF, Qureshi SA. Protein-losing enteropathy caused by baffle obstruction after Mustard's operation. Br Heart J 1988;59:69-72.

2 Qureshi SA, Kirk CR, Lamb RK, Arnold R, Wilkinson $\mathrm{JL}$. Balloon dilatation of the pulmonary valve in the first year of life in patients with tetralogy of Fallot: a preliminary study. Br Heart J 1988;60:232-5.

3 Fischer DR, Park SC, Neches WH, et al. Successful dilatation of a stenotic Blalock-Taussig anastomosis by percutaneous transluminal balloon angioplasty. Am J Cardiol 1985;55:861-2.

4 Fontan F, Quaegebeur J, Ottenkamp J, Sourdille N, Choussat A, Brom GA. Repair of tricuspid atresia in 100 patients. J Thorac Cardiovasc Surg 1983;85: $647-60$.

5 Kirklin JW, Barratt-Boyes BG. Cardiac surgery. New York: Wiley Medical, 1986:877.

6 Kay PH, Capuani A, Franks R, Lincoln C. Experience with the modified Blalock-Taussig operation using polytetrafluoroethylene (Impra) grafts. Br Heart J 1983;49:359-63.

7 Newfield EA, Waldman JD, Paul MH, et al. Pulmonary vascular disease after systemic-pulmonary arterial shunt operations. Am J Cardiol 1977;39:715-21. 